\title{
A novel large cell-sized stent with slim delivery for combined side-by-side and stent-in-stent placement in malignant hilar biliary obstruction
}

A novel approach combining simultaneous side-by-side and stent-in-stent (SBSIS) placement is a promising option for high-grade malignant hilar biliary obstruction that requires triple metal stent placement [1-2]. This method can reduce technical difficulty by avoiding the inability to place the second metal stent and reducing the number of passes through the stent mesh [2]. Although currently there are no specialized metal stents for this technique, a novel braided stent with slim delivery (Niti-S Large Cell SR Slim Delivery; TaeWoong Medical, Seoul, Korea) ( $\triangleright$ Fig. 1 ) was recently developed. This stent has a large cell size that facilitates the passage of stent mesh during the stent-in-stent (SIS) procedure [3] and has a 6-Fr delivery system that enables simultaneous side-by-side (SBS) placement. Here, we report an initial case of SBSIS placement using this metal stent for malignant hilar biliary obstruction.

A 69-year-old man with unresectable pancreatic cancer developed jaundice as a result of a Bismuth type IV malignant hilar biliary obstruction due to liver metastases. For biliary stenting, endoscopic retrograde cholangiopancreatography was performed. Following the insertion of the guidewires into the left, right anterior, and right posterior hepatic ducts across the stricture, the two delivery systems were simultaneously inserted into the left and right posterior hepatic ducts and the stents were placed one by one in a SBS configuration. Then the guidewire was inserted into the right anterior hepatic duct through the mesh of the posterior stent, using the initially placed guidewire of the anterior duct as a landmark. Finally, the third metal stent was placed into the right anterior hepatic duct in a partial SIS configuration ( $\triangleright$ Fig. 2 and $\triangleright$ Video 1 ). There were no adverse events, and no recurrent biliary obstruction was observed during the follow-up period.
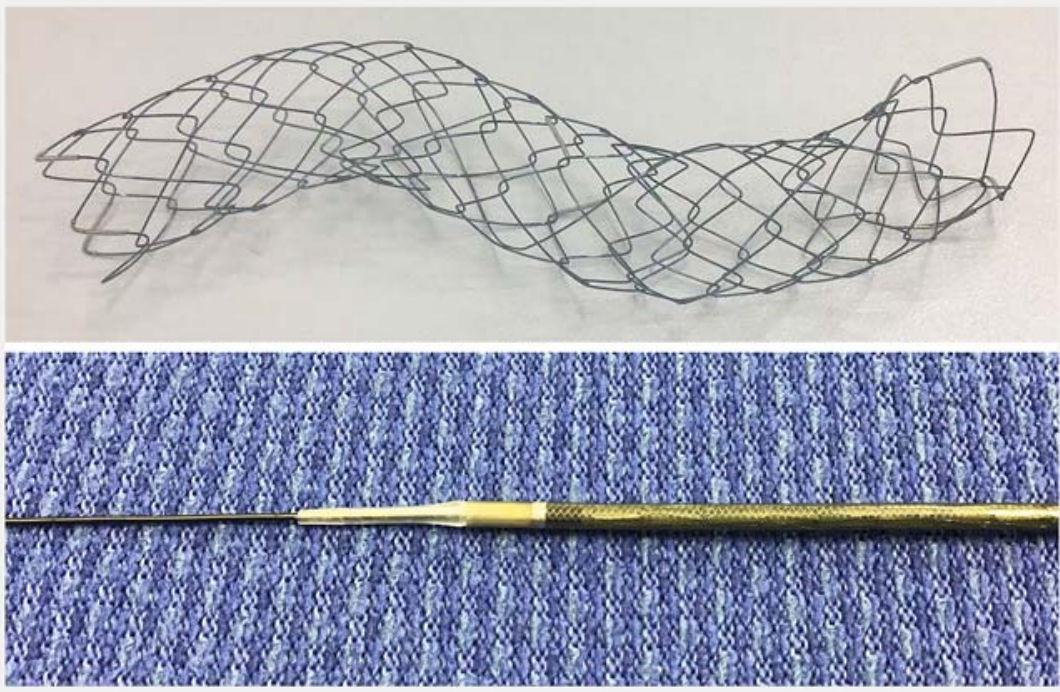

- Fig. 1 Novel, uncovered, braided large cell-sized metal stent with a 6-Fr thin, tapered delivery system (TaeWoong Medical, Seoul, Korea).
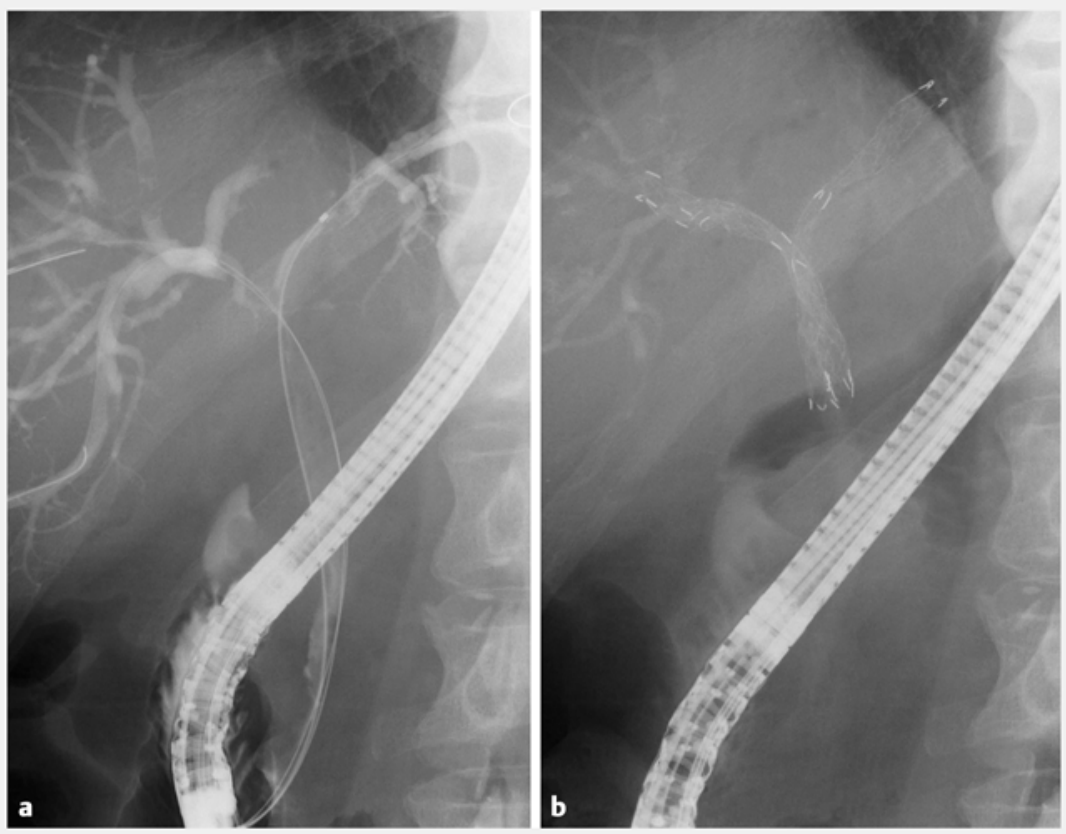

- Fig. 2 a Endoscopic retrograde cholangiography showing a Bismuth type IV malignant hilar biliary obstruction. b Triple metal stenting into the left hepatic, right posterior hepatic, and right anterior hepatic ducts using the combined side-by-side and stent-in-stent technique. 


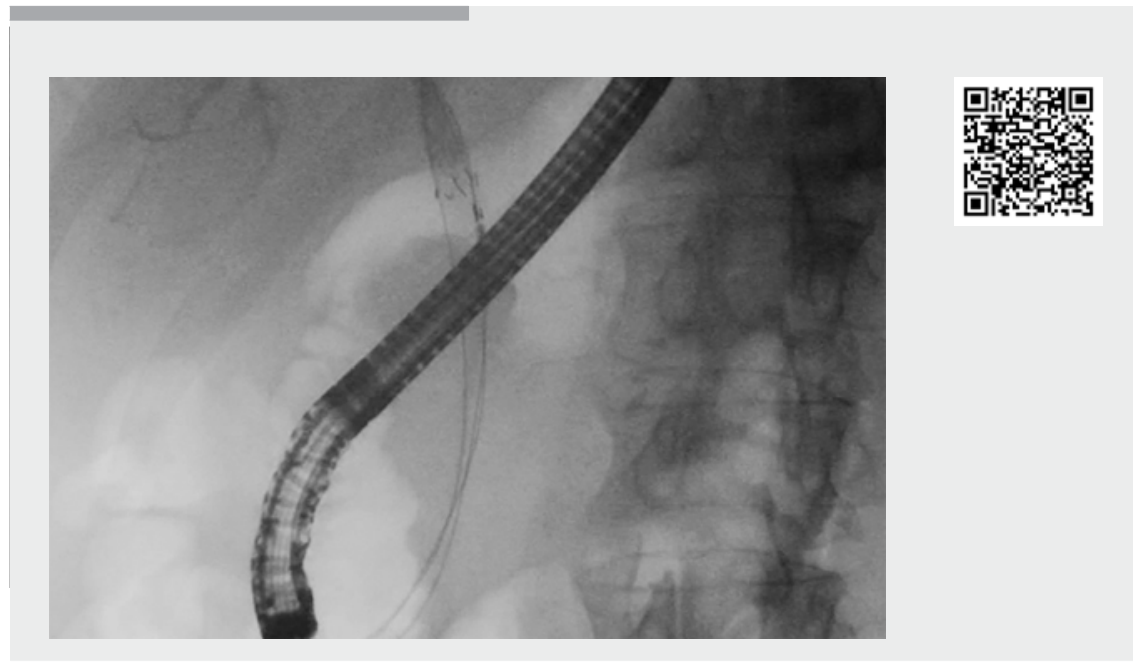

$\checkmark$ Video 1 After simultaneous side-by-side placement into the left and right posterior hepatic ducts, a third stent was placed into the right anterior hepatic duct through the mesh of the posterior stent in a partial stent-in-stent configuration.

Because the novel metal stent is good for use in the SBS and SIS technique, it can be suitable for SBSIS placement.

Endoscopy_UCTN_Code_TTT_1AR_2AZ

\section{Competing interests}

None

The authors

Tadahisa Inoue, Mayu Ibusuki, Rena Kitano, Yuji Kobayashi, Kiyoaki Ito, Masashi Yoneda Department of Gastroenterology, Aichi Medical University, Nagakute
Corresponding author

\section{Tadahisa Inoue, MD}

Department of Gastroenterology, Aichi Medical University, 1-1 Yazakokarimata, Nagakute, Aichi 480-1195, Japan Fax: +81561633208

tinoue-tag@umin.ac.jp

\section{References}

[1] Koshitani T, Nakagawa S, Konaka Y et al. Endoscopic deployment of multiple $(\geq 3)$ metal stents for unresectable malignant hilar biliary strictures. Endosc Int Open 2019; 7: E672-E677

[2] Inoue T, Ibusuki M, Kitano R et al. Combined side-by-side and stent-in-stent method for triple metal stenting in patients with malig- nant hilar biliary obstruction. Dig Endosc 2019. doi:10.1111/den.13448

[3] Kogure H, Isayama H, Nakai Y et al. High single-session success rate of endoscopic bilateral stent-in-stent placement with modified large cell Niti-S stents for malignant hilar biliary obstruction. Dig Endosc 2014; 26: 93-99

\section{Bibliography}

DOI https://doi.org/10.1055/a-1015-6522

Published online: 8.10.2019

Endoscopy 2020; 52: E104-E105

(c) Georg Thieme Verlag KG

Stuttgart · New York

ISSN 0013-726X

\section{ENDOSCOPY E-VIDEOS}

https:|/eref.thieme.de/e-videos

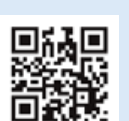

Endoscopy E-Videos is a free access online section, reporting on interesting cases and new techniques in gastroenterological endoscopy. All papers include a high quality video and all contributions are freely accessible online.

This section has its own submission website at https://mc.manuscriptcentral.com/e-videos 